\title{
Study on fatigue life and fracture behaviour of fibreglass reinforced composites
}

\author{
K.A. Zakaria ${ }^{1 *}$, R.H. Jimit ${ }^{1}$, S.N.R. Ramli ${ }^{1}$, A.A. Aziz ${ }^{1}$, O. Bapokutty ${ }^{1}$ and \\ M.B. Ali ${ }^{1}$ \\ ${ }^{1}$ Faculty of Mechanical Engineering, Universiti Teknikal Malaysia Melaka, \\ 76100 Durian Tunggal, Melaka Malaysia \\ *Email: kamarul@utem.edu.my \\ Phone: +6062346606; Fax: +6062346884
}

\begin{abstract}
The material used in vehicle parts could significantly affect the vehicle efficiency. Fibreglass reinforced composites are among the materials that can be used to manufacture the components due to their excellent lightweight properties. Composite structures may undergo fatigue failure when subjected to a certain number of cyclic loading, which normally occurs below the ultimate strength of the material. However, studies on this material's behaviour remain lacking, including on its integrity under fatigue loading. This paper aims to emphasize a study on the effect of fibre orientation on fatigue strength of fibreglass reinforced composites (FGRC), which are $\left[ \pm 45^{\circ}\right]$ and $\left[0 / 90^{\circ}\right]$. The composite is fabricated from unidirectional glass fibre and epoxy resin using a hand lay-up technique. The experimental test is carried out at room temperature according to ASTM D3039 for tensile test at rate $5 \mathrm{~mm} / \mathrm{min}$ and ASTM D3479 for fatigue test at R=0.1 subjected to constant amplitude loadings. The results were presented in the form of S-N curves, showing that $\left[0 / 90^{\circ}\right]$ orientation has a higher fatigue strength as a function of fibre orientation. The results show that the mechanical properties and fatigue behaviour were significantly affected by the fibre orientation of the FGRC.
\end{abstract}

Keywords: Fibreglass reinforced composite; fibre orientation; fatigue life; fracture

\section{INTRODUCTION}

Composite materials are defined as materials which consist of a combination of two or more materials that result in better properties than those of the individual components used alone [1]. The main advantages of composite materials are their high strength and stiffness, as well as low density when compared with isotropic materials [2-7]. This allows for a weight reduction in the manufacturing finished part. In previous years, few researches have focused on composite materials especially the glass fibre to determine the fatigue strength and failure mechanisms of the material. There are a few factors that affect the behaviour of the material which are mostly due to the material design and environment effects $[8,9]$. From the aspect of environment effect towards the strength of the material, moisture content and temperature influences the adhesive strength of fibrematrix interface and the strength of a polymer matrix [10-13]. The material properties and the behaviour under fatigue loading are not only affected by the material design such as delamination, matrix failure and fibre fracture, but other factors can also give the significant effects $[14,15]$. The significant factors can be loading rate, mean stress, load frequency, thickness, fibre volume, and fibre orientation [16-21]. 
Fatigue is the degradation of material properties which happens when the material is experiencing the cyclic loading, thus causing damages and cracks in the material [2224]. Composite materials are designed to reduce the effect of fatigue failure, but they are still subjected to fatigue loadings. One reason among others is because the failure of composites is sudden and without prior notice, therefore it is important to understand and predict the fatigue life of composites $[1,8,15]$. The fatigue life is the number of cycles of alternating stress that is required to cause failure to the test specimen [25]. Many important structures and components such as aircrafts and other automotive parts are subjected to cyclic loading during usage [26] and failure in most of the structural materials are due to fatigue [27]. Composites also respond to fatigue such as metal and other elements. The thickness of the lamination determines the impact damage and fatigue of the material [6, 28-30], but it is not only the actual design of the component that affects how the composite responses to fatigue. The material properties such as fibre arrangement, volume fraction on both fibre and matrix, and fibre and interface properties also affect the response [14-20]. Other factors such as off-axis angle, load phase shift, and stress concentration can affect the fatigue strength of continuous fibre reinforced composites [31]. Towards the development of fibre reinforced composite as a replacement for metal and alloy, Prashanth et al., [16] had studied the influence of fibre orientation and thickness on tensile properties of laminated woven glass fibre reinforced composites. Another study done by Hussain J. Al-Alkawi et al., [32] found differences in the mechanical strength of fibre glass reinforced composites with orientation angles compared to those which were discontinuous and randomly oriented.

Seyyedvahid et al. [33] studied the material's behaviour of the composites which are affected by the orientation of each layer. Another study by Nyman T. [34] focused on the test approach of the difference between multidirectional and unidirectional composites behaviour in every new lay-up. Another study done by A. Bernasconi et al. [35] showed that the different orientation of reinforcing fibre affects the development of damage mechanisms, whereby if more fibre is aligned parallel to the loading direction, less damage will accumulate during fatigue life, and less stiffness degradation will subsequently occur. Due to the presence of the anisotropy and heterogeneity, damage occurred at different stress levels. Those stress levels are dependent on the fibre orientation of the lamination [34]. The mechanical properties of a composite material are significantly influenced by the fibre orientation [36]. This motivates the current work to conduct a study on the effect of fibre orientation on fatigue behaviour of fibreglass reinforced composites (FGRC) strength as a function of fibre orientation. In this experimental study, the fibre orientations tested were $\left[0 / 90^{\circ}\right]$ and $\left[ \pm 45^{\circ}\right]$. The samples for the tensile test and fatigue test were fabricated using the hand lay-up technique and tested on an Instron 8872 Universal Testing Machine. The fibre orientation was analysed experimentally, and its relationship with the observed fatigue life and fracture behaviour was investigated.

\section{METHODS AND MATERIALS}

\section{Fabrication of Composites}

The material investigated is fibreglass reinforced composite, with the specimen prepared and fabricated in the lab. A number of steps are carried out during the infusion process. These processes can be divided into several fragments, namely, process materials, supplies infusion process, and the finishing process. The raw materials used in this work are E glass fibre (woven), Epoxy resin LY 556, and corresponding hardener (HY951). 
The fabrication of the composites is carried out through the hand lay-up technique. Fibres of $\left[ \pm 45^{\circ}\right]$ and $\left[0 / 90^{\circ}\right]$ measuring $60 \mathrm{~cm} \times 60 \mathrm{~cm}$, with four pieces for each orientation, were prepared as shown in Figure 1.

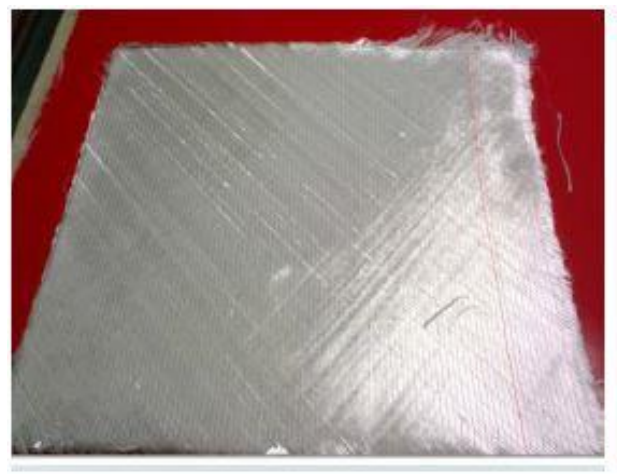

(a)

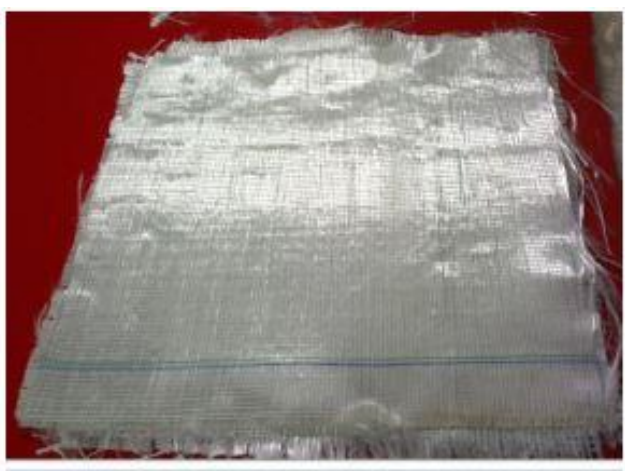

(b)

Figure 1. Fibreglass laminated composites with different orientations:

(a) $\left[ \pm 45^{\circ}\right]$ and (b) $\left[0 / 90^{\circ}\right]$.

A cleaned glass surface is polished six times using the "mold release" to facilitate the process of disassembling the specimen at the end of the fabrication process. Glass fibres that have been cut are arranged on the surface of the mirror. Each layer of fibreglass is sprayed with adhesive glue to attach each layer to each other. This step is repeated until the fourth layer. Next, peel ply layer was affixed after the fourth layer is set, as shown in Figure 2. Purpose of the peel ply is to level the surface of the fibre composite.

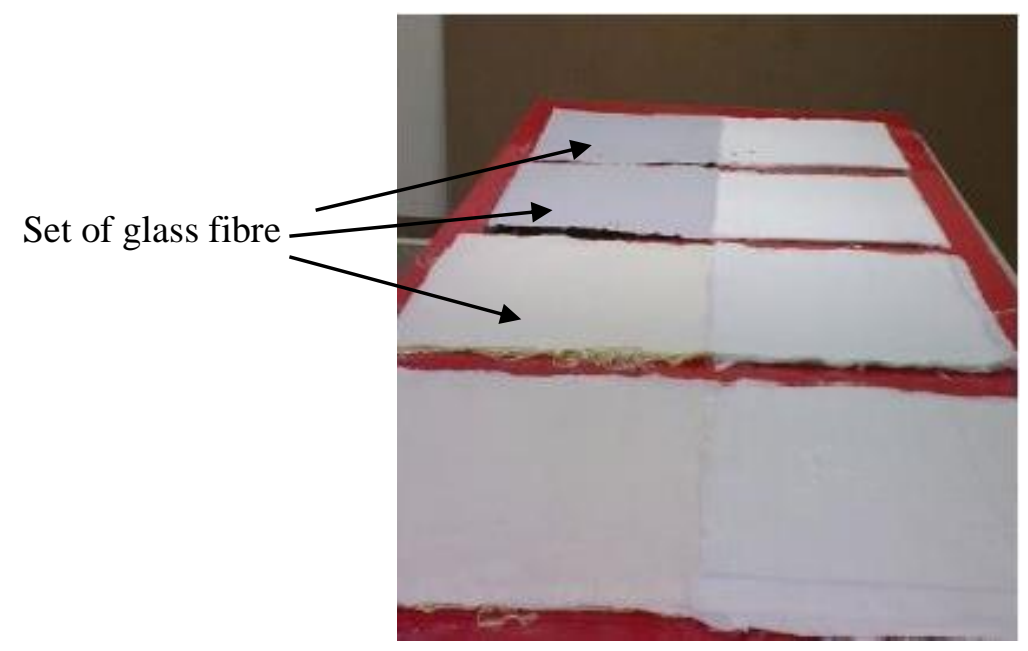

Figure 2. Preparing composite laminate.

Drop test is conducted to identify leaks in the system fabrication, as shown in Figure 3. Infusion technique requires an airtight layer to prevent defects in the specimen. Once no air is detected in the system, the material such as resin and hardener mixtures are mixed thoroughly. Infusion is run after all the equipment is ready. The mixture of resin and hardener is allowed to soak up every surface of the glass fibre. The curing process requires one day at room temperature. After the resin has dried, the process of demolding is carried out to remove the composite. 


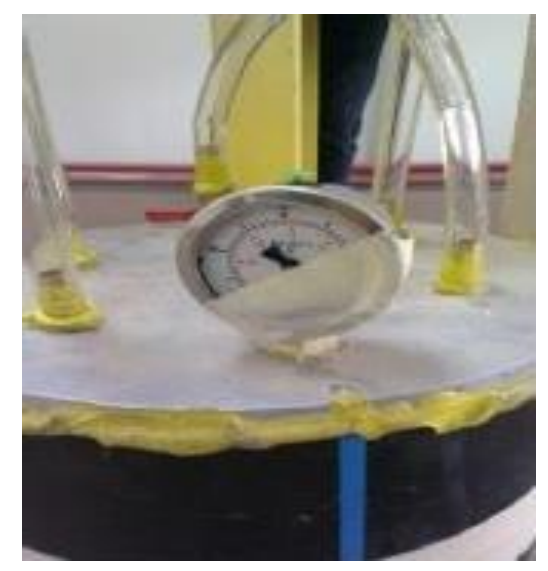

Figure 3. Drop test is carried out to identify leaks in fabrication.

\section{Experimental Procedure}

After fabrication, the test specimens were subjected to tensile test and constant amplitude fatigue test. A tensile test is performed according to ASTM D 3039 [37]. The specimens were cut to meet the specifications of $250 \mathrm{~mm}$ length, $25 \mathrm{~mm}$ width, and $3 \mathrm{~mm}$ thickness as shown in Figure 4 . The test is operated at constant head-speed tests of $5 \mathrm{~min} / \mathrm{mm}$. The average tensile properties were determined from three specimen tests on each type of orientation.

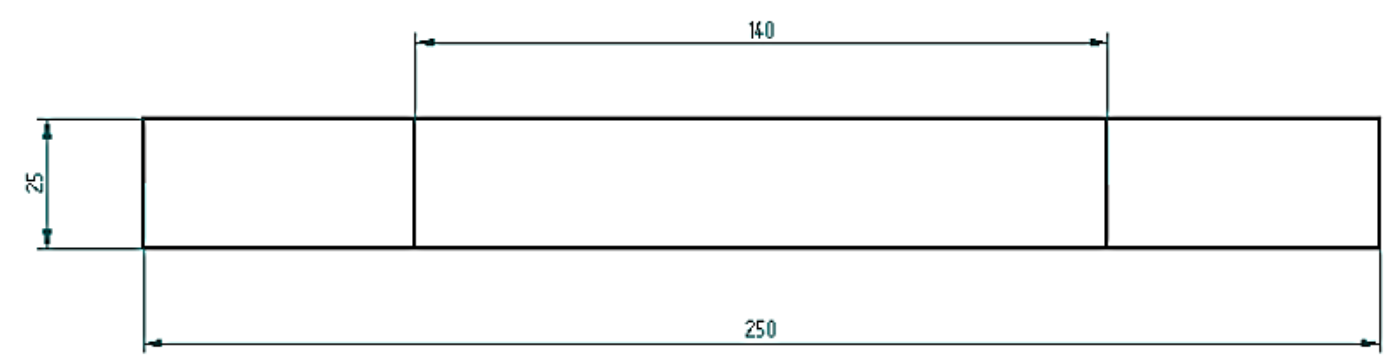

Figure 4. Standard tensile test specimen dimensions as per ASTM D 3039.

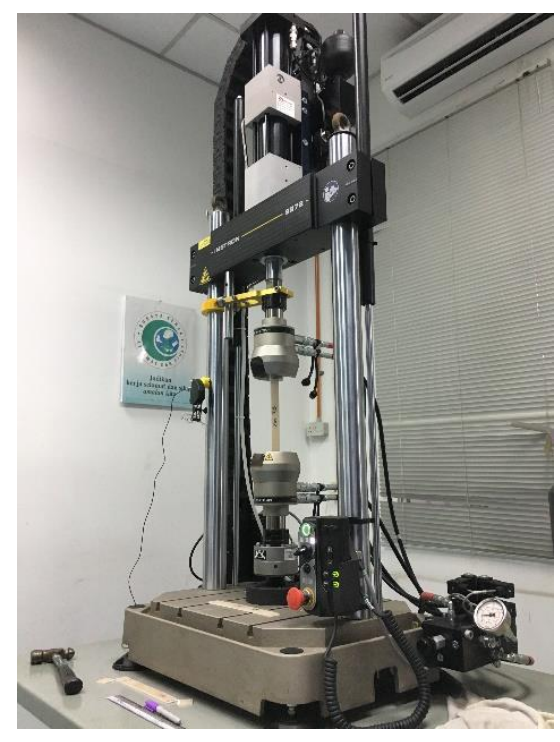

Figure 5. Universal testing machine Instron 8872. 
After obtaining the mechanical properties of each orientation, a fatigue test is performed according to ASTM D 3479. The test was conducted under constant amplitude loading using sine wave at $1.0 \mathrm{~Hz}$ frequency and stress ratio, $\mathrm{R}=0.1$. The load is obtained as percentage from the value of the UTS which ranged from 50-90\%. Both tests were conducted using an Instron 8872 as shown in Figure 5. The fractography test is carried out on the specimens after the tensile and fatigue tests are done. Fractography is carried out to closely observe the surface structure of the specimen. Through the micrograph image, fractography observation on matrix and reinforcement failure can be analysed. Two types of fractography approaches were used in this study which are observation using an inverted microscope as shown in Figure 6, and gross observation using human sight.

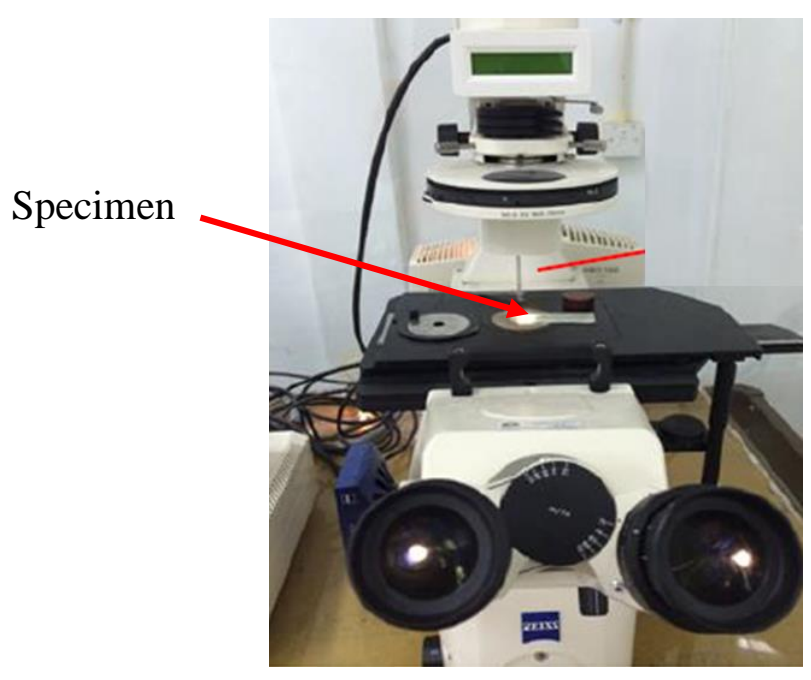

Figure 6. Fractography observation for fibreglass reinforced composite.

\section{RESULTS AND DISCUSSION}

\section{Effect of Fibre Orientation}

Table 1 shows the tabulation of results from the tensile test of fibreglass reinforced composites (FGRC) with $\left[ \pm 45^{\circ}\right]$ and $\left[0 / 90^{\circ}\right]$ orientation. The $\left[0 / 90^{\circ}\right]$ orientation of FGRC epoxy composites has the highest ultimate tensile strength, which is $293 \mathrm{MPa}$, followed by $\left[ \pm 45^{\circ}\right]$, which is about $40 \%$ lower than $\left[0 / 90^{\circ}\right]$. The $\left[0 / 90^{\circ}\right]$ orientation also has the highest value for the yield strength, $\sigma_{\mathrm{y}}$, and elastic modulus, $\mathrm{E}$.

Table 1. The average value of mechanical properties of FGRC with different fibre orientations.

\begin{tabular}{cccc}
\hline $\begin{array}{c}\text { Angle of fibre } \\
\text { Orientation }\left({ }^{\circ}\right)\end{array}$ & $\begin{array}{c}\text { UTS, } \\
\sigma_{\text {ult }}(\mathrm{MPa})\end{array}$ & $\begin{array}{c}\text { Yield Strength, } \\
\sigma_{\mathrm{y}}(\mathrm{MPa})\end{array}$ & $\begin{array}{c}\text { Modulus of elasticity, } \\
\text { E (GPa) }\end{array}$ \\
\hline$\left[ \pm 45^{\circ}\right]$ & 175 & 173 & 6.4 \\
{$\left[0 / 90^{\circ}\right]$} & 293 & 290 & 7.9 \\
\hline
\end{tabular}

Figure 7 shows a stress-strain curve of the fibre orientation $\left[ \pm 45^{\circ}\right]$ and $\left[0 / 90^{\circ}\right]$ from the tensile tests. The stress-strain curve experienced by FGRC $\left[ \pm 45^{\circ}\right]$ is divided into two parts, linear and non-linear. At the beginning of the stress-strain curve, the specimen undergoes the linear elastic part, which occurs before it reaches the point of non-linear 
first portion. In the elastic region, the specimen may rebound or return to its original shape even when load is applied. This phenomenon shows that the specimen did not fail to fully crack. In the non-linear region, the specimen undergoes plastic changes. In addition, the specimen did not return back to its original shape. When a load is applied continuously, failure occurred when reaching $\sigma_{\text {ult }}[30]$. Based on the average stress-strain graph in Figure 7 , the fibreglass with $\left[ \pm 45^{\circ}\right]$ orientation reached $\sigma_{\text {ult }}$ at $175 \mathrm{MPa}$ while $\left[0 / 90^{\circ}\right]$ orientation reached $\sigma_{\text {ult }}$ at $293 \mathrm{MPa}$. The FGRC of $\left[0 / 90^{\circ}\right]$ orientation showed a higher value of Young's modulus compared to $\left[ \pm 45^{\circ}\right]$ orientation. The curve plotted in Figure 5 showed that the value for yield strength is only $1 \%$ lower than the UTS value which indicates that each tested specimen undergoes failure or fully cracks when subjected to the maximum load. The curve in Figure 7 showed that FGRC with $\left[0 / 90^{\circ}\right]$ orientation is stronger compared to FGRC with $\left[ \pm 45^{\circ}\right]$. Data from Table 1 above shows that $\left[0 / 90^{\circ}\right]$ orientation has higher mechanical properties compared to $\left[ \pm 45^{\circ}\right]$ orientation due to the longitudinal samples where much of the resistance against loading occurs in shell layers, due to load enduring capability of oriented fibres. Because shell layers compromise a greater percentage of the cross section than the core layer, tensile properties in the longitudinal direction is greater as compared with the transverse direction. The strengths of continuous and unidirectional fibrous composites are highly anisotropic, and such composites are normally designed to be loaded along the high strength, longitudinal direction. However, during in-service applications, transverse tensile loads may also be present. Under these circumstances, premature failure may result in extremely low transverse strength, which sometimes lies below the tensile strength of the matrix [8, 3436].

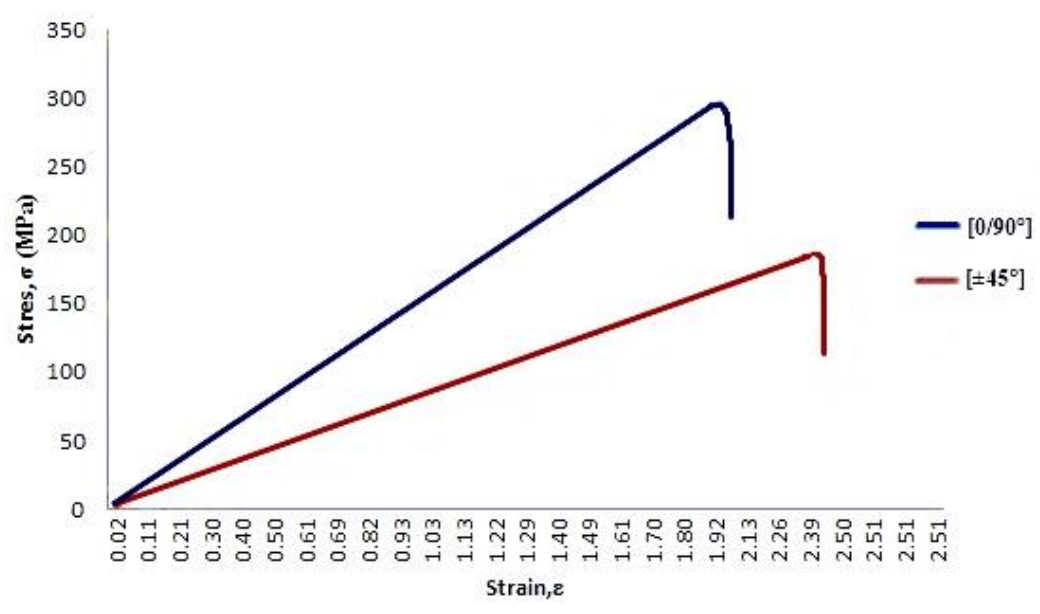

Figure 7. Stress-strain curve for $\left[ \pm 45^{\circ}\right]$ and $\left[0 / 90^{\circ}\right]$ orientation.

The fatigue result of the specimens having different orientations is reported in Figure 8 below. The stress life (S-N curve) is plotted for $\log \sigma_{a}$ vs. $\log N_{f}$. The S-N curve was developed using curve fitting of tabular data following the Basquin equation [38], which can be written as Eq. (1).

$$
\sigma_{a}=\left(N_{f}\right)^{b}
$$

where $\sigma a$ is the stress amplitude, $a$ and $b$ are the material constants, and $N_{f}$ is the number of cycles to failure. From the curve fitting, the values of the material constants $a$ and $b$ 
were determined at $468.96 \mathrm{MPa}$ and -0.119 for $\left[0 / 90^{\circ}\right]$, whereas for $\left[ \pm 45^{\circ}\right]$, the value is $280.1 \mathrm{MPa}$ and -0.119 . The S-N curves showed that glass fibre composites with $\left[0 / 90^{\circ}\right]$ orientation is stronger compared to those with $\left[ \pm 45^{\circ}\right]$ orientations.

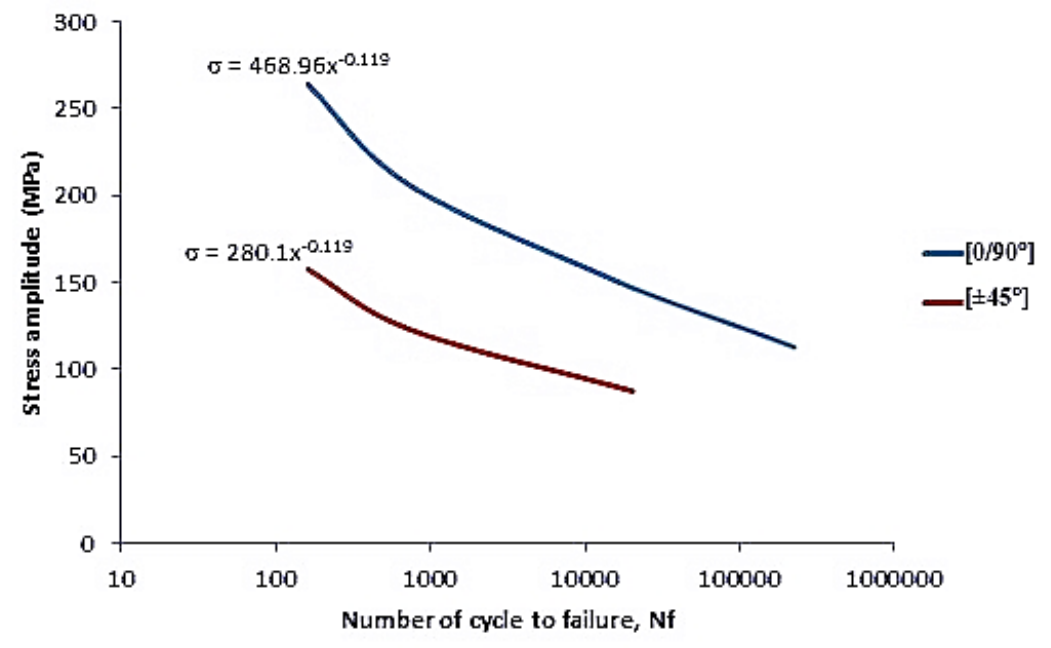

Figure 8. S-N curve for FGRC of $\left[ \pm 45^{\circ}\right]$ orientation and $\left[0 / 90^{\circ}\right]$ orientation.

Previous studies by Keisuke Tanaka et al., [30] found that the applied force which causes fatigue failure behaviour stems from a plastic change in the material, cracks, or failure, which is followed by the crack propagation of a brittle material between the fibres and the matrix layer. This statement describes and explains the trends that appear to result from the S-N curve for the study of FGRC $\left[ \pm 45^{\circ}\right]$ and $\left[0 / 90^{\circ}\right]$. The S-N curves showed the trend of fatigue behaviour in both specimens. The S-N curve graph showed that the fibreglass composite with $\left[0 / 90^{\circ}\right]$ orientation experienced higher fatigue strength which reached 500,000 cycles compared to FGRC with $\left[ \pm 45^{\circ}\right]$ orientation with respect to the number of cycles before failure.

\section{Fractography Observation}

The fracture surfaces of the tensile and fatigue tests recorded via normal observation and inverted microscope $50 \mu \mathrm{m} \times 50 \mu \mathrm{m}$ are as shown in Figure 9 and Figure 10, respectively. Fractography observation indicates that the structural failures experienced by the composite fibreglass specimen $\left[ \pm 45^{\circ}\right]$ and $\left[0 / 90^{\circ}\right]$ were examined more closely. The behaviour of failure for both tensile and fatigue tests demonstrated the failure of the reinforcing material and the matrix when the load reaches the maximum yield at which the composites are no longer able to accommodate the force applied.

For the tensile test, the difference of failure for $\left[ \pm 45^{\circ}\right]$ and $\left[0 / 90^{\circ}\right]$ can be seen as shown in Figure 9 above. For FGRC $\left[ \pm 45^{\circ}\right]$, the failure is in the corner of the glass fibre at a $45^{\circ}$ angle, as shown in Figure 9 (a) above. For $\left[ \pm 45^{\circ}\right]$ orientation, many fibres pulled out from the matrix can be seen in the skin layer, while many fibres are exposed to the fracture surface in the core layer. In transverse direction specimen, a crack propagates along interfaces or in the matrix. In $\left[ \pm 45^{\circ}\right]$ specimen, a crack propagates $45^{\circ}$ along interfaces or horizontally in the matrix. For $\left[0 / 90^{\circ}\right]$ orientation, the crack propagation rate is slightly lower than that of $\left[ \pm 45^{\circ}\right]$ because the $\left[ \pm 45^{\circ}\right]$ does not have the core layer. In $\left[0 / 90^{\circ}\right]$ orientation, a crack propagates along interfaces or in the matrix [30]. 


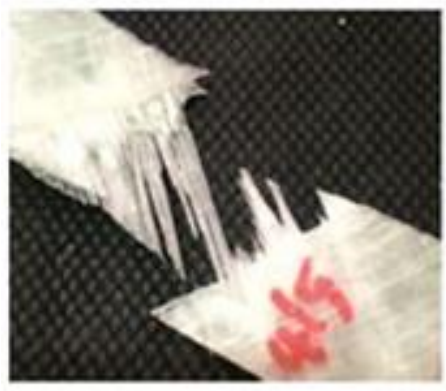

(a)

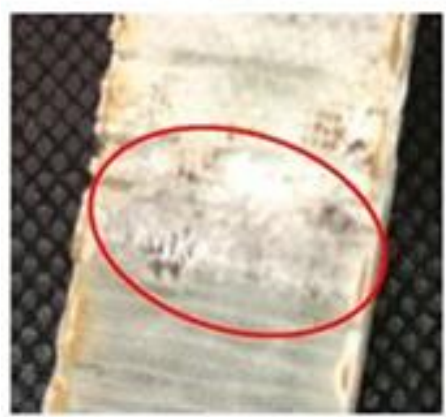

(c)

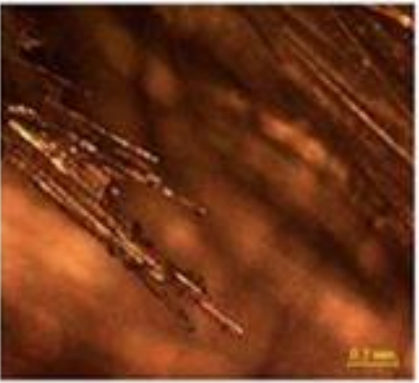

(b)

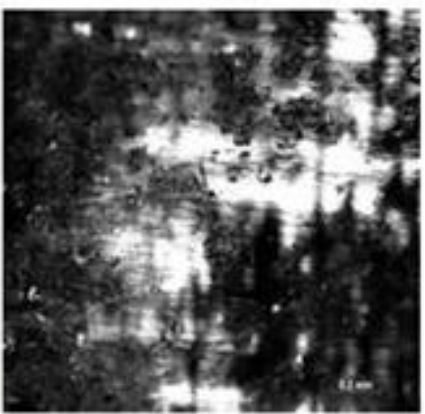

(d)

Figure 9. Fractography for tensile test of FGRC $\left[ \pm 45^{\circ}\right]$ by (a) normal observation, (b) inverted microscope and, FGRC $\left[0 / 90^{\circ}\right]$ by (c) normal observation, (d) inverted microscope.

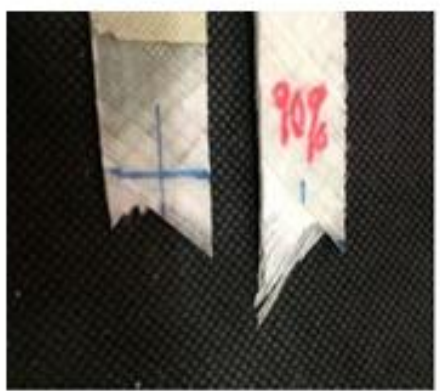

(a)

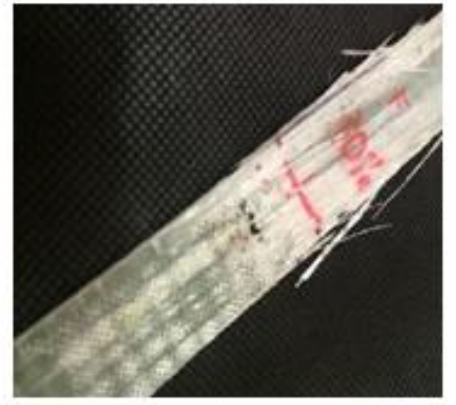

(c)

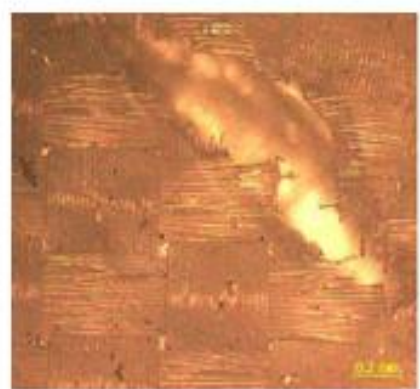

(b)

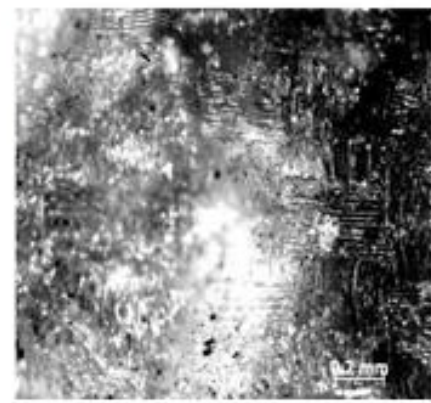

(d)

Figure 10. Fractography for fatigue test of FGRC $\left[ \pm 45^{\circ}\right]$ by (a) normal observation, (b) inverted microscope, and FGRC $\left[0 / 90^{\circ}\right]$ by (c) normal observation, (d) inverted microscope. 
Meanwhile, for the fatigue test shown in Figure 10 below, the failure behaviour of FGRC $\left[ \pm 45^{\circ}\right]$ and $\left[0 / 90^{\circ}\right]$ is slightly different from the behaviour of the tensile test. The observation indicates that crack propagation occurs in different directions until reaching the maximum size of the cracks tip region. In the $\left[ \pm 45^{\circ}\right]$ orientation's skin layer, the surface of pulled out fibres is coated by the matrix, indicating fatigue cycling which promotes debonding at the interface between fibre and matrix. Based on the propagation of fatigue cracks, the cracks move slowly through the specimen. Therefore, the occurrence of cracking would require a certain time for full failure. Once the cracks are crossed or reach maximum size, specimen fractures will occur. In $\left[0 / 90^{\circ}\right]$ orientation, macroscopic crack propagation path was nearly perpendicular to the loading axis. For the $\left[ \pm 45^{\circ}\right]$ orientation, the crack path was inclined because the crack often propagated along inclined fibres.

\section{CONCLUSIONS}

In this paper, it was attempted to make a correlation between the fibre orientation and the fatigue behaviour of FGRC. The effect of fibre orientation on the fatigue strength of fibreglass reinforced composite materials was presented in both the tensile and fatigue tests. The results obtained from the experiment indicate that specimens with $\left[0 / 90^{\circ}\right]$ orientation is stronger than $\left[ \pm 45^{\circ}\right]$ orientation. Specimen sustained greater load in $\left[0 / 90^{\circ}\right]$ orientation than in other orientations due to the fibre alignment in longitudinal direction. This contributes to a higher number of cycles of failure for specimens with $\left[0 / 90^{\circ}\right]$ orientation compared to those with $\left[ \pm 45^{\circ}\right]$ orientation. Meanwhile, fractography surface shows that failure occurs when the composite reinforcement no longer accommodates the load applied. The weak bonding between matrix and reinforcement results in fast crack propagation in addition to a high applied load. Fracture surfaces clearly showed that the fibre aligned in longitudinal structure, and the crack propagation path was nearly perpendicular to the loading axis. However, testing and analysing more data in future work is recommended to achieve a better correlation and more accurate results.

\section{ACKNOWLEDGEMENTS}

The authors would like to express their gratitude to Universiti Teknikal Malaysia Melaka, UTeM for supporting these research activities under grant RAGS/1/2014/TK01/ FKM/B00068.

\section{REFERENCES}

[1] Sabu T, Kuruvilla J, Malhotra S, Goda K, Sreekala M. Polymer Composites, Macro-and Microcomposites. ISBN 978-3-527-32624-2; 2012.

[2] Mazumdar S. Composites manufacturing: materials, product, and process engineering: CrC press; 2001.

[3] Roslan S, Hassan M, Rasid Z, Zaki S, Daud Y, Aziz S, et al. Mechanical properties of bamboo reinforced epoxy sandwich structure composites. International Journal of Automotive and Mechanical Engineering. 2015;12:2882.

[4] Ismail AE, Aziz CA. Tensile strength of woven yarn kenaf fiber reinforced polyester composites. Journal of Mechancial Engineering and Sciences. 2015;9.

[5] Roslan SAH, Hassan MZ, Rasid ZA, Zaki SA, Daud Y, Aziz S, et al. Mechanical properties of bamboo reinforced epoxy sandwich structure composites. 
International Journal of Automotive and Mechanical Engineering. 2015;12:288292.

[6] Asif Iqbal AKM, Arai Y. Study on low-cycle fatigue behavior of cast hybrid metal matrix composites. International Journal of Automotive and Mechanical Engineering. 2015;11:2504-14.

[7] Wan Dalina WAD, Mariatti M, Mohd Ishak ZA, Mohamed AR. Comparison of properties of mwcnt/carbon fibre/ epoxy laminated composites prepared by solvent spraying method. International Journal of Automotive and Mechanical Engineering. 2014;10:1901-9.

[8] Campbell FC. Structural composite materials: ASM international; 2010.

[9] Milne I, Ritchie RO, Karihaloo BL. Comprehensive structural integrity: Cyclic loading and fatigue: Elsevier; 2003.

[10] Jia N, Kagan VA. Effects of time and temperature on the tension-tension fatigue behavior of short fiber reinforced polyamides. Polymer composites. 1998;19:40814.

[11] Mouzakis DE, Zoga H, Galiotis C. Accelerated environmental ageing study of polyester/glass fiber reinforced composites (GFRPCs). Composites part B: engineering. 2008;39:467-75.

[12] Barbouchi S, Bellenger V, Tcharkhtchi A, Castaing P, Jollivet T. Effect of water on the fatigue behaviour of a pa66/glass fibers composite material. Journal of Materials Science. 2007;42:2181-8.

[13] Adebisi AA, Maleque MA, Rahman MM. Metal Matrix Composite Brake Rotor: Historical Development and Product Life Cycle Analysis. International Journal of Automotive and Mechanical Engineering. 2011;4:471-80.

[14] Mallick PK. Fiber-reinforced composites: materials, manufacturing, and design: CRC press; 2007.

[15] Vassilopoulos AP, Keller T. Introduction to the fatigue of fiber-reinforced polymer composites. Fatigue of Fiber-reinforced Composites: Springer; 2011. p. $1-23$.

[16] Banakar P, Shivananda H, Niranjan H. Influence of fiber orientation and thickness on tensile properties of laminated polymer composites. International Journal of Pure and Applied Sciences and Technology. 2012;9:61-8.

[17] MM R, KJT J. Residual strength of chop strand mats glass fiber/epoxy composite structures: effect of temperature and water absorption. International Journal of Automotive and Mechanical Engineering. 2011;4:504-19.

[18] Mallick P, Zhou Y. Effect of mean stress on the stress-controlled fatigue of a short E-glass fiber reinforced polyamide-6, 6. International Journal of Fatigue. 2004;26:941-6.

[19] Khan AS, Colak OU, Centala P. Compressive failure strengths and modes of woven S2-glass reinforced polyester due to quasi-static and dynamic loading. International Journal of Plasticity. 2002;18:1337-57.

[20] Sutherland L, Soares CG. Impact on low fibre-volume, glass/polyester rectangular plates. Composite Structures. 2005;68:13-22.

[21] Kasim AN, Selamat MZ, Daud MAM, Yaakob MY, Putra A, Sivakumar D. Mechanical properties of polypropylene composites reinforced with alkaline treated pineapple leaf fibre from Josapine cultivar. International Journal of Automotive and Mechanical Engineering. 2016;13:3157-67.

[22] Campbell FC. Fatigue and fracture: understanding the basics: ASM International; 2012. 
[23] Zakaria KA, Abdullah S, Ghazali MJ, Azhari CH. Influence of spectrum loading sequences on fatigue life in a high-temperature environment. Engineering Failure Analysis. 2013;30:111-23.

[24] Zakaria K, Abdullah S, Ghazali M. A Review of the Loading Sequence Effects on the Fatigue Life Behaviour of Metallic Materials. Journal of Engineering Science and Technology Review. 2016;9:189-200.

[25] Schmid SR, Hamrock BJ, Jacobson BO. Fundamentals of Machine Elements: SI Version: CRC Press; 2014.

[26] Tomita Y, Morioka K, Iwasa M. Bending fatigue of long carbon fiber-reinforced epoxy composites. Materials Science and Engineering: A. 2001;319:679-82.

[27] Khan SU, Munir A, Hussain R, Kim J-K. Fatigue damage behaviors of carbon fiber-reinforced epoxy composites containing nanoclay. Composite Science and Technology. 2010;70:2077-85.

[28] Tian K, Dasgupta PK. Determination of oxidative stability of oils and fats. Analytical chemistry. 1999;71:1692-8.

[29] Rathnakar G, Shivanand H. Effect of thickness on flexural properties of epoxy based glass fiber reinforced laminate. International Journal of Science and Technology. 2012; 2(6): 409-12.

[30] Fatchurrohman N, Sulaiman S, Sapuan SM, Ariffin MKA, Baharuddin BTHT. Analysis of a metal matrix composites automotive component. International Journal of Automotive and Mechanical Engineering. 2015;11:2531-40.

[31] Quaresimin M, Talreja R. Fatigue of fiber reinforced composites under multiaxial loading. Polymer Composites in the Aerospace Industry. 2014:155.

[32] Al-Alkawi HJ, Al-Fattal DS, Ali A-JH. Types of the fiber glass-mat on fatigue characteristic of composite materials at constant fiber volume fraction: Experimental determination. Al-Khawarizmi Engineering Journal. 2012;8(3):112.

[33] Mortazavian S, Fatemi A. Effects of fiber orientation and anisotropy on tensile strength and elastic modulus of short fiber reinforced polymer composites. Composites Part B: Engineering. 2015;72:116-29.

[34] Nyman T. Composite fatigue design methodology: a simplified approach. Composite Structures. 1996;35:183-94.

[35] Bernasconi A, Davoli P, Basile A, Filippi A. Effect of fibre orientation on the fatigue behaviour of a short glass fibre reinforced polyamide-6. International Journal of Fatigue. 2007;29:199-208.

[36] Tanaka K, Kitano T, Egami N. Effect of fiber orientation on fatigue crack propagation in short-fiber reinforced plastics. Engineering Fracture Mechanics. 2014;123:44-58.

[37] Materials ACD-oC. Standard test method for tensile properties of polymer matrix composite materials: ASTM International; 2008.

[38] Zakaria KA. Elevated temperature fatigue life investigation of aluminium alloy based on the predicted SN curve. Jurnal Teknologi, UTM. 2013:75-9. 